\title{
EMISAR: An Absolutely Calibrated Polarimetric L- and C-band SAR
}

Christensen, Erik Lintz; Skou, Niels; Dall, Jørgen; Woelders, Kim; Jørgensen, Jan Hjelm; Granholm, Johan; Madsen, Søren Nørvang

Published in:

I E E E Transactions on Geoscience and Remote Sensing

Link to article, DOI:

$10.1109 / 36.729356$

Publication date:

1998

Document Version

Publisher's PDF, also known as Version of record

Link back to DTU Orbit

Citation (APA):

Christensen, E. L., Skou, N., Dall, J., Woelders, K., Jørgensen, J. H., Granholm, J., \& Madsen, S. N. (1998).

EMISAR: An Absolutely Calibrated Polarimetric $L$ - and C-band SAR. I E E E Transactions on Geoscience and Remote Sensing, 36(6), 1852-1865. https://doi.org/10.1109/36.729356

\section{General rights}

Copyright and moral rights for the publications made accessible in the public portal are retained by the authors and/or other copyright owners and it is a condition of accessing publications that users recognise and abide by the legal requirements associated with these rights.

- Users may download and print one copy of any publication from the public portal for the purpose of private study or research.

- You may not further distribute the material or use it for any profit-making activity or commercial gain

- You may freely distribute the URL identifying the publication in the public portal 


\title{
EMISAR: An Absolutely Calibrated Polarimetric $L$ - and $C$-band SAR
}

\author{
Erik Lintz Christensen, Member, IEEE, Niels Skou, Senior Member, IEEE, Jørgen Dall, Kim Wildt Woelders, \\ Jan Hjelm Jørgensen, Johan Granholm, Member, IEEE, and Søren Nørvang Madsen, Member, IEEE
}

\begin{abstract}
EMISAR is a high-resolution $(2 \times 2 \mathrm{~m})$, fully polarimetric, dual-frequency ( $L$ - and $C$-band) synthetic aperture radar (SAR) system designed for remote-sensing applications. The SAR is operated at high altitudes on a Gulfstream G-3 jet aircraft. The system is very well calibrated and has low sidelobes and low cross-polar contamination. Digital technology has been utilized to realize a flexible and highly stable radar with variable resolution, swath width, and imaging geometry. Thermal control and several calibration loops have been built into the system to ensure system stability and absolute calibration. Accurately measured antenna gains and radiation patterns are included in the calibration. The processing system is developed to support data calibration, which is the key to most of the current applications. Recent interferometric enhancements are important for many scientific applications.
\end{abstract}

Index Terms - Absolute calibration, mapping geometry, polarimetry, remote sensing, resolution, synthetic aperture radar (SAR) system design.

\section{INTRODUCTION}

$\mathbf{S}$ INCE the first unclassified papers on synthetic aperture radar (SAR) [1], technological advances have made it economically feasible to build SAR systems optimized for civilian applications. Today, the benefits of SAR for remote sensing are widely recognized and a number of SAR's have been built not only for research, but also for operational applications [2].

In 1986, the Electromagnetics Institute of the Technical University of Denmark, Lyngby, started the development of a high-resolution airborne $C$-band SAR. Primary requirements were system calibration, high resolution, and significant flexibility in the acquisition geometry such that the instrument could serve as an underflight instrument for the European Space Agency (ESA) satellite SAR system (ERS-1). The design and initial tests of that system have been previously published [3]. Fully polarimetric capability (i.e., four complex data channels per frequency) was completed, tested, and calibrated in late 1993 . The polarimetric $L$-band SAR was calibrated in early 1995, and the dual-frequency system has been used for scientific applications since the summer of 1995 .

Manuscript received June 10, 1996; revised November 17, 1997. The development of the $C$-band SAR was supported by the Thomas B. Thriges Foundation, while the enhancement of the system to dual-frequency $(C$ and $L$-band) polarimetric capability was supported by the Danish Technical Research Council and the European Union, represented by the Institute for Remote Sensing Applications of the Joint Research Centre (JRC), Ispra, Italy.

The authors are with the Danish Center for Remote Sensing, Department of Electromagnetic Systems (formerly Electromagnetics Institute), Technical University of Denmark, DK-2800 Lyngby, Denmark (e-mail: lintz@emi.dtu.dk).

Publisher Item Identifier S 0196-2892(98)05629-0.
Today, the EMISAR system is a research radar used as follows:

1) as a testbed for coherent radar technology (including polarimetry and interferometry);

2) for research in remote-sensing techniques at the Danish Center for Remote Sensing (DCRS);

3) to collect high-quality SAR data for international scientific programs.

For instance, the system was used in the EMAC program conducted by ESA [4], [5].

This paper has the following purposes:

1) to outline the capabilities and the performance of the system;

2) to report on the approach taken in the design;

3) to serve as a reference paper for users of EMISAR data.

Section II explains the operation of the system and the various possibilities in mapping geometry, polarization, etc. that allow adaptation to different measurement requirements. Section III describes the requirements driving the design and the actual performance of the system. Section IV is an overview of the system, outlining the subsystems that are most important to the performance. Section V offers a description of the off-line processing with emphasis on the calibration. Section VI presents the performance verification, some applications of the system are presented in Section VII, and they are followed by a brief outline of ongoing airborne SAR activities at the DCRS in Section VIII.

\section{FUNCTIONALITY}

\section{A. Operation}

EMISAR has been designed for remote-sensing applications requiring high data quality during different mapping conditions, such as mapping geometry, resolution, swath width, different polarizations, etc. A mission may be composed of a number of scenes with different requirements to these conditions.

The SAR is operated on a Gulfstream G-3. The use of a jet aircraft offers optimum conditions for mapping geometry and data quality, but it also constrains the flexibility in changing altitudes and flight directions. When the mapping of different target areas close to each other requires a change in the flight track, a detour may be necessary to take the aircraft to the required track.

In order to assure operational flexibility, a set of parameters are defined for each scene, including information describing 
the target area (latitude, longitude, viewing angle, etc.) and the desired operating mode for the $L$ - and $C$-band sensors (polarimetric mode, resolution, transmitted signal encoding type, etc.). System configuration, start and stop of the data recording, internal calibration before and after the scene, etc., are performed automatically.

\section{B. Mapping Geometry}

The system is normally operated at high altitudes (e.g., $41000 \mathrm{ft}$ ) to permit a wide target area to be mapped with a minimum variation of the angle of incidence. Operation at high altitudes also offers near-perfect mapping conditions since severe air turbulence, having an impact on data quality, is then very unusual. Operation at lower altitudes is an option for applications in which the best signal-to-noise ratio, or a particular mapping geometry, have priority.

The range of look angles (equal to the angles of incidence at the target if a flat earth is assumed) is limited by the antenna radiation pattern. At $L$-band, the flexibility in antenna depression angle is small since the antenna pattern is so wide in elevation that small deviations from the optimum orientation may cause unwanted left/right ambiguity or multipath propagation [6]. The radiation pattern of the $C$-band antenna permits several modes to be utilized, including an ERS-1 underflight mode operating with small angles of incidence (where the effective swath width becomes limited by the antenna pattern), full swath width, high-resolution mapping out to $80-\mathrm{km}$ range, and extended swath width, reduced resolution mapping out to $80-\mathrm{km}$ range. The available swath width is partly dependent on the choice of resolution, as explained in the following section. When accurately calibrated data are required, the look angles are normally kept within the $30-60^{\circ}$ range at both frequencies, but at $C$-band, look angles down to $20^{\circ}$ in near range or up to $80^{\circ}$ in far range can be requested.

The mapping geometry is described by the viewing (or aspect) angles and the target area. Fig. 1 shows the target area. The system has a three-axes stabilized antenna (either $C$ - or $L$-band), which in the horizontal plane, normally looks perpendicular to the flight track (left looking) to acquire the data at zero Doppler shift. However, data recording at a fixed, stabilized squint angle (looking slightly forward or backward) is also supported, for use when the aircraft drift angle is outside the maximum possible antenna yaw correction range. The system also has two flush-mounted $C$-band antennas. The direction to the target area from these antennas is determined by the aircraft drift angle.

The target center ground distance (TCGD) is the desired horizontal distance from the flight track ground projection to the "target center." The radar data collection starts at waypoint 1 and stops at waypoint 2 . In between these points the aircraft should fly along the actual flight track either by the autopilot or, as will be described later, by the radar controlling the flight track. Waypoints $\alpha$ and $\beta$ are used by the aircraft (auto)pilot for navigation. The lead-in distance (from waypoint $\alpha$ to waypoint 1) is typically used to stabilize the aircraft after a turn or a change in altitude, and to perform the premap calibration data recording. The lead-in distance must usually be at least

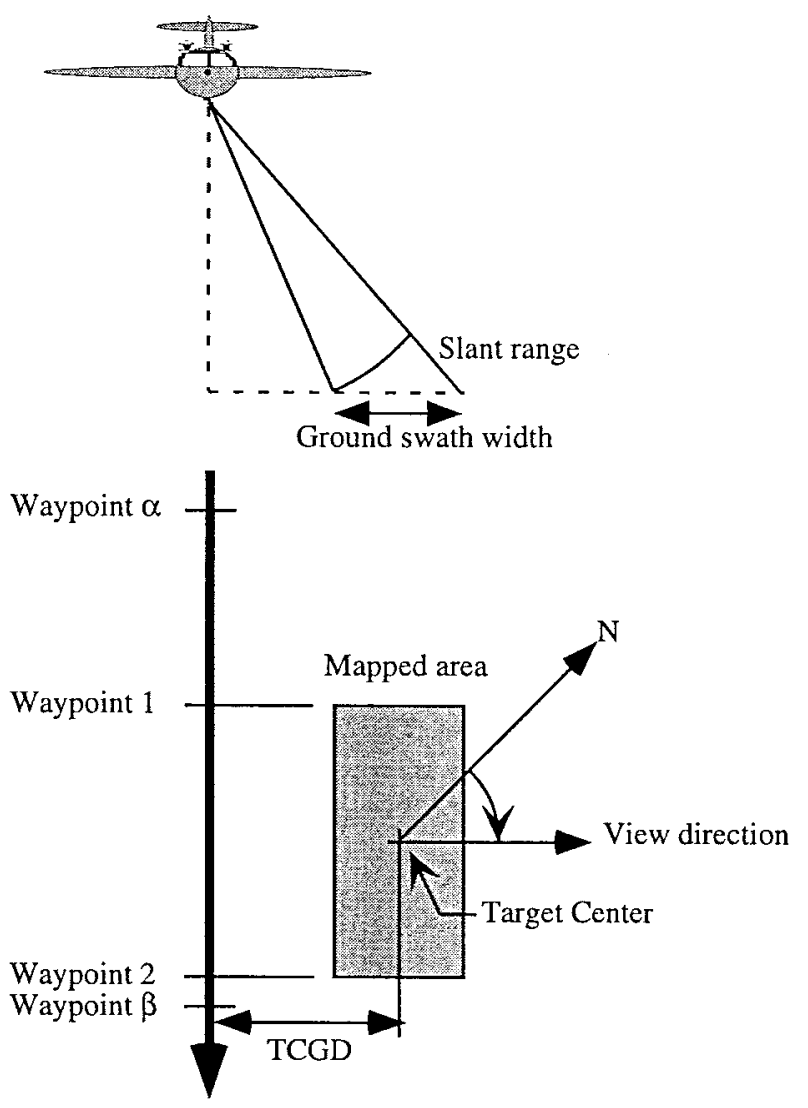

Flight track

Fig. 1. Mapping area geometry.

$40 \mathrm{~km}$ unless subsequent target areas are mapped from exactly the same flight track. The pilot needs an additional $25 \mathrm{~km}$ to guide the aircraft onto the flight track.

\section{Signal Options}

The sensor supports various signal options, in particular choices of polarizations, interferometric modes, and resolution modes. The proper choice of these options can have significant impact on the applicability of the data for a particular purpose, and they reflect the necessity of keeping the total data rate within the capacity of the high-density digital tape recorder (HDDT).

The system supports the following polarization modes.

1) Quad, in which the transmit polarization is alternately horizontal $(\mathrm{H})$ and vertical $(\mathrm{V})$ and data from all four transmit and receive polarization combinations are stored on tape.

2) Dual, in which the transmit polarization is alternated from pulse to pulse and only the two copolarized channels are stored on tape.

3) Single, in which only one polarization is transmitted and received.

4) Single transmit, dual-channel receive mode, primarily intended for cross-track interferometry (XTI) applications in which the receivers are connected to two different antennas. 
The sensor can be operated in several resolution modes. The transmitted pulse can be almost any constant amplitude waveform within the constraints of the transmitter duty cycle and the system bandwidth, including linear frequency sweeps (up or down sweeping) with 25-, 50-, and 100-MHz sweep. In range, optional filtering and subsampling (decimation) can be carried out before the data are stored in the range line buffers, i.e., resolution can be traded for swath width. The range line buffers hold 8192 samples. In azimuth, prefiltering to $1.5-\mathrm{m}$ sample spacing is normally applied to limit the data rate, but a finer sampling is possible, e.g., $0.75-\mathrm{m}$ sample spacing, if only one frequency is recorded, only two polarizations are recorded at each frequency, or the swath is reduced. Normally, data are recorded on tape with $1.5 \times 1.5-\mathrm{m}$ (range and azimuth) sample spacing, and the unprocessed slant range swath width is $12 \mathrm{~km}$. In wide swath modes, the sample spacing is $3.0 \times 1.5 \mathrm{~m}$ or $6.0 \times 1.5 \mathrm{~m}$, and the corresponding swath widths are 24 and $48 \mathrm{~km}$.

The operational modes also include a number of interferometric modes. One of these modes is designed to facilitate repeat-pass aircraft interferometry by providing very accurate flight track control, as described in Section IV-C. Additional flush-mounted antennas have been installed to provide a $C$-band single-pass interferometric capability to allow the generation of high-resolution elevation maps. Details of interferometric modes and capabilities are discussed in [7].

The full range of different modes, except single-pass interferometry, are supported for both $L$ - and $C$-bands. Simultaneous operation at both frequencies is also fully supported, except for the fact that the present pod can only accommodate one stabilized antenna. Dual-frequency data are presently acquired either by changing the antenna between two mappings or by mounting the $L$-band antenna in the pod and using one of the flush-mounted antennas for $C$-band polarimetry. However, the present azimuth prefilters do not support the data from the flush-mounted antennas with range-varying Doppler centroid. Therefore, simultaneous $L$ - and $C$-band polarimetry necessitates reduced swath operation. The results stated in this paper for polarimetric performance are based on the three-axes stabilized antennas.

\section{PERFORMANCE}

Several requirements have driven this design, some of which were discussed in [3]. Requirements were added for polarimetric performance and for the second frequency. The original requirements called for a $C$-band VV-polarized system to provide an ERS-1 underflight system. The system was specified to provide numerous mapping modes and geometries, including different ranges of incidence angles and resolutions. The actual parameters of the polarimetric SAR system are listed in Table I, while the argumentation for some of the choices are given in the following. Important parameters are discussed further in subsequent sections.

To provide reasonable swath widths at the steep incidence angles corresponding to satellite geometries, a Gulfstream G-3 aircraft with an operational ceiling of $45000 \mathrm{ft}$ has been chosen and the design is optimized for operation at altitudes in the range from 30000 to $45000 \mathrm{ft}$.
TABLE I

EMISAR $C$ - AND $L$-BAND System Performance

\begin{tabular}{|c|c|c|}
\hline \multicolumn{3}{|l|}{ System Parameters } \\
\hline Frequency & C-Band, $5.3 \mathrm{GHz}$ & L-Band $1.25 \mathrm{GHz}$ \\
\hline TWT output power & $2 \mathrm{~kW}$ & $6 \mathrm{~kW}$ \\
\hline Receiver noise figure & $1.5 \mathrm{~dB}$ & $1.5 \mathrm{~dB}$ \\
\hline System loss (Tx $+\mathrm{Rx}$ side) & $(3.1+0.8)=3.9 \mathrm{~dB}$ & $(3.4+0.9)=4.3 \mathrm{~dB}$ \\
\hline Pulse length & $0.64-20 \mu \mathrm{s}$ & $0.64-20 \mu \mathrm{s}$ \\
\hline Max bandwidth & $100 \mathrm{MHz}$ & $100 \mathrm{MHz}$ \\
\hline Antenna gain, incl. feeder loss & $26.0 \mathrm{dBi}$ & $17.1 \mathrm{dBi}$ \\
\hline Azimuth $3 \mathrm{~dB}$ beam width & $2.4^{\circ}$ & $10^{\circ}$ \\
\hline Elevation pattern width & $31^{\circ}$ & $42^{\circ}$ \\
\hline Polarization & Fully polarimetric & Fully polarimetric \\
\hline Antenna cross polarization & $<-30 \mathrm{~dB}$ & $<-35 \mathrm{~dB}$ \\
\hline Azimuth ambiguity & $<-30 \mathrm{~dB}$ & $<-30 \mathrm{~dB}$ \\
\hline Resolution in slant range & 2,4 or $8 \mathrm{~m}$ & 2,4 or $8 \mathrm{~m}$ \\
\hline Resolution in azimuth & 2,4 or $8 \mathrm{~m}$ & 2,4 or $8 \mathrm{~m}$ \\
\hline Swath width & 12,24 or $48 \mathrm{~km}$ & 12,24 or $48 \mathrm{~km}$ \\
\hline Flight altitude & Typically $41,000 \mathrm{ft}$ & Typically $41,000 \mathrm{ft}$ \\
\hline Real-time processing & Full resolution & Full resolution \\
\hline Noise equivalent $\beta_{\mathrm{ON}}$, distributed target, $20 \mathrm{~km}$ & $-36 \mathrm{~dB}\left(\mathrm{~m}^{2} / \mathrm{m}^{2}\right)$ & $-45 \mathrm{~dB}\left(\mathrm{~m}^{2} / \mathrm{m}^{2}\right)$ \\
\hline PSLR (Table 2 and Section VI) & $-30 \mathrm{~dB}$ & $-25 \mathrm{~dB}$ \\
\hline ISLR (Table 2 and Section VI) & $-28 \mathrm{~dB}$ & $-21 \mathrm{~dB}$ \\
\hline Intrinsic cross-talk terms & $<-30 \mathrm{~dB}$ & $<-35 \mathrm{~dB}$ \\
\hline Calibrated cross-talk terms & $<-35 \mathrm{~dB}$ & TBD \\
\hline Weight, Equipment inside cabin & \multicolumn{2}{|c|}{$600 \mathrm{~kg}$} \\
\hline Pod & \multicolumn{2}{|c|}{$240 \mathrm{~kg}$} \\
\hline \multirow{2}{*}{$\frac{115 \mathrm{~V}, 400 \mathrm{~Hz}}{28 \mathrm{~V}, \mathrm{DC}}$} & \multicolumn{2}{|c|}{$5 \mathrm{~kW}, 6 \mathrm{kVA}$} \\
\hline & \multicolumn{2}{|c|}{$1 \mathrm{~kW}$} \\
\hline \multirow[t]{2}{*}{ Equipment inside cabin } & \multicolumn{2}{|c|}{$3 \times 19^{\prime \prime}$ racks, $\mathrm{H}=1.40 \mathrm{~m}$} \\
\hline & \multicolumn{2}{|c|}{$4.59 \times 0.81 \times 0.55 \mathrm{~m}$} \\
\hline
\end{tabular}

To serve as a reference system for future satellite systems and to simulate existing satellite systems, a 2-m resolution in range and azimuth is required, with a capability to reduce the resolution and increase the swath width. The 2-m resolution after sidelobe weighting (Hamming) requires approximately $100 \mathrm{MHz}$ of total bandwidth. As a data acquisition window of 8192 complex range samples is required, a degradation of the range resolution from 2 to 4 or $8 \mathrm{~m}$ increases the slant range swath (before range compression loss) from 12 to 24 or $48 \mathrm{~km}$.

The system sensitivity required for the $C$-band singlepolarization configuration is to map distributed targets with a characteristic backscatter coefficient of $\beta_{0}=-30 \mathrm{~dB}$ $\left(\mathrm{m}^{2} / \mathrm{m}^{2}\right)$ at an incidence angle of $\theta=65^{\circ}$ (altitude $12.5 \mathrm{~km}$, slant range $=30 \mathrm{~km}$ ) with better than $10-\mathrm{dB}$ signal-tonoise ratio, which corresponds to a signal-to-noise ratio of $10 \mathrm{~dB}$ for a point target of $\sigma=0.1 \mathrm{~m}^{2}$ at $80-\mathrm{km}$ range. The system sensitivity is somewhat lower in the polarimetric configuration since the transmitter is alternating between the two polarizations and the antenna system has higher losses. Furthermore, during mapping, the antenna is normally pointed to give good calibration accuracy also at the swath edges at some cost in sensitivity. The absolute calibration of the system is required to be better than $\pm 1 \mathrm{~dB}$ to meet the needs of most geophysical measurements [8].

Additional requirements on the polarimetric performance are largely based on an analysis performed at NASA's Jet Propulsion Laboratory (JPL), Pasadena, CA, in support of the SIR-C mission [9]. A polarimetric channel balance better than $\pm 0.4 \mathrm{~dB}$ and $\pm 10^{\circ}$, in combination with a 30 - $\mathrm{dB}$ cross-talk isolation, were found to preserve the observed polarization 

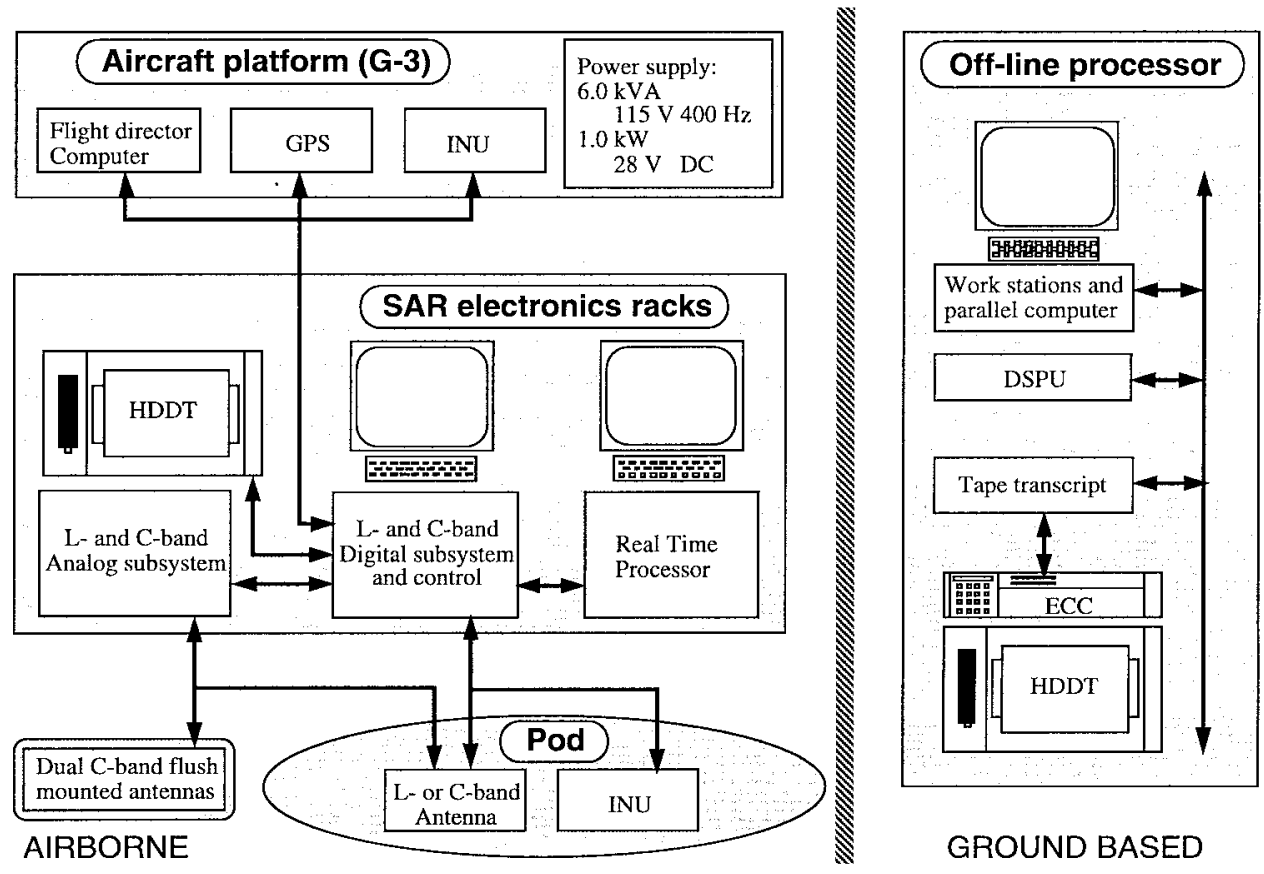

GROUND BASED

Fig. 2. EMISAR system overview.

signature for the applications investigated in that study. As inherent channel signal-to-noise ratio for extended targets seldom exceeds $30 \mathrm{~dB}$, it does not make sense to specify a much better polarimetric isolation, whereas a better phase imbalance specification seems to be both reasonable (balancing amplitude and phase "noise" leads to a phase imbalance specification of $2.7^{\circ}$ ) and technically feasible.

Other added requirements included sidelobe specifications and azimuth ambiguity specifications. Peak sidelobes of the system were originally specified at $-30 \mathrm{~dB}$, and the integrated sidelobes at $-15 \mathrm{~dB}$. Initial images from the single channel version of the radar showed these specifications to provide excellent image quality.

A second longer wavelength was needed for several reasons. The backscatter coefficient for vegetation generally increases with the biomass per hectare, however, at $C$-band, this relationship saturates for quite small biomass values. A longer wavelength corresponds to a larger saturation value (see, for example, [10]). Also, a longer wavelength is desired for studying the polarimetric response of natural surfaces as most natural targets are rough relative to the Rayleigh criterion $(h>\lambda /(8 \cos \theta))$ at $C$-band. To comply with radio frequency allocations and maintain image quality similar to $C$-band and keeping the complexities in aircraft installation and radio frequency interference (RFI) at a reasonable level, $L$-band $(24 \mathrm{~cm})$ is a good choice for a second wavelength.

\section{SySTEM OVERVIEW}

\section{A. System Units}

The SAR consists of an airborne segment, including the sensor subsystem (two sensors), and a ground-based segment with the off-line processing facility. Both segments play an

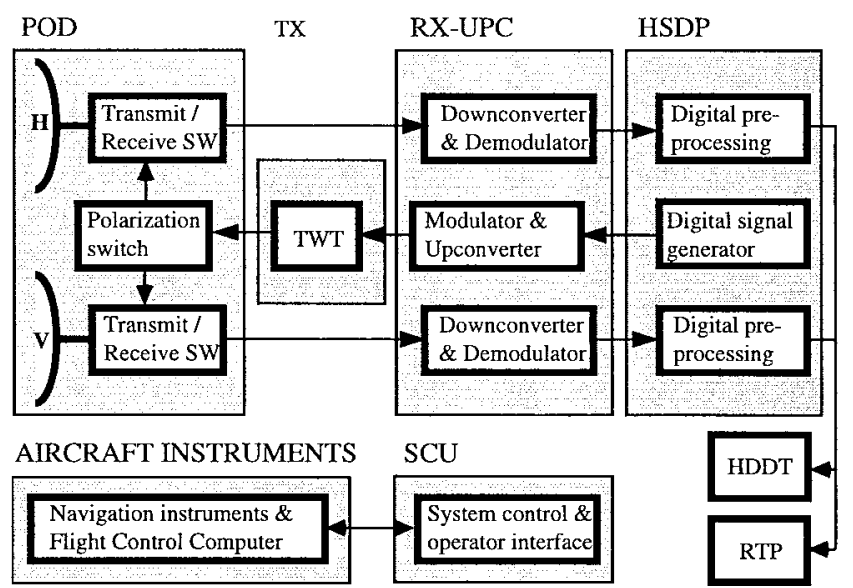

Fig. 3. C-band (or $L$-band) polarimetric SAR overview diagram. The dual-polarized antenna is illustrated by two separate antennas.

important role in the task of acquiring high-quality data, and they are described in subsequent sections with emphasis on the sensor subsystem. An overview of the complete system is shown in Fig. 2, while Fig. 3 displays a simplified block diagram of one of the sensors.

The aircraft platform provides primary power, navigation data [P-code global positioning system (GPS), inertial navigation unit (INU), altimeter, etc.], and access to the flight director computer, thus permitting precise flight track control.

The electronics racks (three 19-in racks for the dualfrequency system located in the aircraft cabin) hold the following: the system control unit (SCU); HDDT; the realtime processor (RTP) displaying images in real time for one polarization; the high-speed digital processor (HSDP, one per frequency) generating system timing, encoding the digital 
radar pulse, interfacing the analog and digital subsystems (D/A conversion of the transmitted signal and A/D conversion of the received signals), preprocessing of the received digitized signals, and interfacing to the HDDT and RTP; the receiver and up-converter (RX-UPC, one per frequency), in which modulation and frequency translation takes place as well as generation of analog reference signals; and the transmitter (TX, one per frequency) performing high-power amplification.

The pod beneath the aircraft contains the dual-polarized antenna system (with the present aircraft installation only one frequency at a time); the polarization switch and the duplexers; the antenna controller operating the three-axes stabilized antenna(s) under SCU control; and the INU used for motion (displacement and attitude) compensation.

Two flush-mounted antennas have been installed (vertically displaced) in front of the pod to support interferometry. This recent installation also permits simultaneous dual-frequency operation ( $L$-band polarimetry from the pod and $C$-band polarimetry from a flush-mounted antenna).

The off-line processing facility takes care of the data digestion from HDDT to a transcription unit performing preprocessing of the ancillary data and generating radar data and ancillary data output files in a standardized format for subsequent processing; and includes, furthermore, fast UNIX workstations and a parallel computer running the polarimetric SAR processing software as well as software for data quality analysis and visualization.

\section{B. Sensor Function}

The operation of the sensor (either $L$ - or $C$-band) can be explained as follows (quad pol mode) Fig. 3. The HSDP generates the radar pulse at baseband. The signal is up-converted by the RX-UPC and amplified by the TX. The transmit polarization $(\mathrm{H}$ or $\mathrm{V})$ is determined by the polarization switch in the pod, which connects the TX to either the H-port or the $\mathrm{V}$-port of the antenna. The echo is received simultaneously in both polarizations and down-converted to baseband by the RXUPC. The RX-UPC contains two receivers: one connected to the H-port of the antenna and one connected to the V-port. The baseband signal is digitized and preprocessed by the HSDP. In each receive channel, the data streams corresponding to the two transmit polarizations are demultiplexed and filtered in azimuth. All four channels are sent to the HDDT interface subsystem, where they are multiplexed with the four channels from the other HSDP and with the ancillary data and, finally, they are stored on tape by the HDDT. The polarimetric channel chosen by the SAR operator is passed to the RTP and displayed in real time.

\section{Subsystems}

The subsystems of particular importance to the sensor performance are briefly described in the following. The description of the subsystems covers both $L$ - and $C$-bands in most cases since the same principles have been applied for the $L$ - and $C$-band subsystems and have been implemented with identical digital subsystems. Differences are mentioned when it is relevant.
Signal Generation, Modulation, and Demodulation: The radar signal with a bandwidth up to $100 \mathrm{MHz}$ is generated at baseband by a digital signal generator that delivers the complex (i.e., $I$ and $Q$ ) signal to a dual 8-bit D/A converter operating at $200 \mathrm{MHz}$. Linear FM, nonlinear FM, and other waveforms used for special purposes are supported. The signal bandwidth depends on the actual range resolution mode and will typically be $100 \mathrm{MHz}$, but 50 and $25 \mathrm{MHz}$ are also supported. The signal duration is limited by the maximum traveling wave tube (TWT) amplifier duty cycle (3\% for both $C$ - and $L$-bands). The time-bandwidth product of the transmitted signal is maximum 2000. The baseband signal is converted to/from a $300-\mathrm{MHz}$ intermediate frequency by conventional quadrature modulators and demodulators and transferred to and retrieved from the radio frequency (1.25 GHz for $L$-band and $5.3 \mathrm{GHz}$ for $C$-band) using a conventional heterodyne approach. All local oscillator, timing, and clock signals are generated from a common $100-\mathrm{MHz}$ stable frequency reference.

Phase Twiddle: The inherent deficiencies of quadrature modulators and demodulators (quadrature imbalance and DC offset) are counteracted by using a phase twiddle strategy, in which the phase of the transmitted signal is incremented by $\pi / 2$ from pulse to pulse in each channel (in the quad polarization mode for instance one $\mathrm{H}$ and one $\mathrm{V}$ pulse is transmitted before the phase is incremented). The phase twiddle causes the received signals to be frequency shifted by $f_{\mathrm{PRF}} / 4$ in the azimuth frequency domain. After the A/D conversion, the received signals are shifted back by $f_{\mathrm{PRF}} / 4$, as part of the motion compensation, canceling any frequency shift induced by the twiddle operation. DC offset from the quadrature demodulator and the $\mathrm{A} / \mathrm{D}$ converter is thereby transferred to $f_{\mathrm{PRF}} / 4$ and can be removed by filtering in the azimuth domain, [11].

Antenna and Polarization Switch: The $C$-band antenna is a dual-polarized $32 \times 7$-element microstrip antenna designed to approximate a modified cosec-squared elevation radiation pattern for optimum illumination of the ground [12], [13]. The $L$-band antenna is a dual-polarized $8 \times 2$-element microstrip antenna. In order to obtain the required bandwidth, the elements used are stacked microstrip patches [14], [15]. The antennas have been optimized for high polarization discrimination and low azimuth ambiguity [6]. Basic antenna specifications are included in Table I.

The polarization switches (one per frequency) are integrated with the duplexers, the receiver protection units, and the lownoise preamplifiers. Their function in polarimetry mode is during transmission to send the radar signal alternately to the $\mathrm{V}$ - and $\mathrm{H}$-ports of the antenna and during reception to guide the received signals from the two ports to the dual receiver. The isolation from the TX to the not used antenna is approximately $60 \mathrm{~dB}$ at $C$-band and $50 \mathrm{~dB}$ at $L$-band. Thus, the system cross talk is determined primarily by the antenna cross-polarization level.

Calibration Circuits: EMISAR employs an internal calibration system that greatly relieves the dependence on external calibration targets: measuring via internal signal loops just before and after mapping calibration of the system within the 


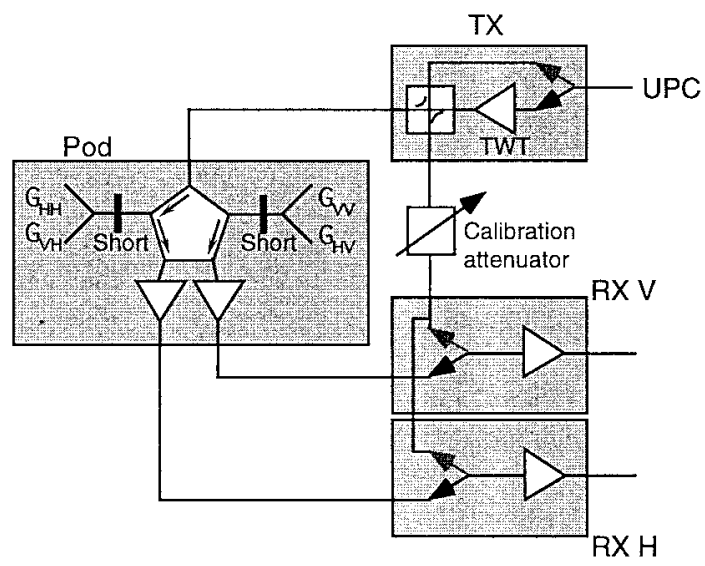

Fig. 4. Block diagram of the polarimetric SAR highlighting the calibration loops.

outer loop can be assured depending only on a few passive components and the stability of the temperature controlled analog system during mapping [16], [17]. Fig. 4 outlines the block diagram, highlighting the calibration issues. The polarization switch is set up for $\mathrm{H}$-transmission. The TX and receiver (RX) switches are shown in the mapping positions (bold), where the signal from the upconverter is routed via the TWT to the polarization switch to be radiated by the antenna. The received signals are routed to the dual receiver. During mapping, the calibration short switches are transparent.

Three calibration loops are used, as follows.

1) Normal: The receivers are fed (through the calibration attenuator) by a sample of the "transmitted pulse" (bold TX switch, shaded RX switches in Fig. 4).

2) Extended outer loop: The pulse from the upconverter is routed directly via a directional coupler in the TX through the polarization switch toward the antenna where it is reflected, by means of shorting switches, back through the polarization switch to the receivers (shaded TX switch, bold RX switches).

3) Extended inner loop: The receivers are fed by a sample of the upconverter pulse (shaded TX and RX switches).

By measuring the "received" signals in the mapping mode and the three different calibration modes, the polarimetric calibration can be carried out [17].

Digital Preprocessing: A dual 8-bit A/D converter module operating at $100 \mathrm{MHz}$ digitizes the analog baseband signals ( $I$ and $Q$ ) received from each $\mathrm{RX}-\mathrm{UPC}$ channel. The $100-\mathrm{MHz}$ complex digital signal is optionally filtered and decimated (subsampling by a factor of two or four for $50-$ or $25-\mathrm{MHz}$ signals, respectively). This filter improves the signal-to-noise ratio as well as increases the swath width when coarser resolution is accepted.

The first stage of azimuth preprocessing is a first-order motion compensation centering the azimuth spectrum around zero frequency, provided the antenna is stabilized perpendicular to the desired reference track. Hardware to perform the similar compensation on signals from squinted antennas is under development. The resulting Doppler centroid is monitored by a subsystem based on the sign-Doppler estimation method [18] to verify the antenna pointing and phase correction. The first-order motion compensation is completely removed again before the off-line processing. The second stage performs lowpass filtering and decimation in azimuth to the final sample spacing. The low-pass filtering improves the signal-to-noise ratio and the azimuth ambiguity level.

Navigation and Motion Compensation: The system acquires aircraft navigation and motion data from various instruments, including INU and GPS. The system is connected to the flight director computer, thus making very precise mapping flight tracks possible. Deviations from the desired track, as defined by the onboard real-time P-code GPS system, can be kept within a few meters. The data are also used for controlling the pulse repetition frequency (assuring constant sample spacing along the ground track), antenna pointing, and first-order motion compensation. The navigation data and the sensor data can be synchronized to within $1 \mathrm{~ms}$ during off-line processing.

Real-time Processor (RTP): This unit is used for verifying proper system function and thus the data quality in real time and to check that the desired target area has been mapped. Further information on the RTP can be found in [19] and [20].

\section{PROCESSING}

The main elements of the data processing chain are data transcription, preprocessing (including calibration), and postprocessing.

\section{A. Basic Processing}

Transcription: Transfer from the nonstandard HDDT tapes to a standardized product is performed by the transcription unit (TSU) consisting of an HDDT drive, an intelligent HDDT interface, and a host computer. The tasks performed by the TSU are as follows: read the raw data from the HDDT tapes or from the disk; preprocess ancillary data and internal calibration data; perform quality assurance; select specified scenes; generate data files with the SAR data and ancillary data in a standardized format; archive data on standard computer tapes (presently Exabyte tapes); and update an internal database. The TSU output data are selected, tested, and formatted according to a standardized specification such that the TSU data users are isolated from sensor updates and get just the SAR data they want and the ancillary information needed to evaluate and use the data.

Preprocessing: Focusing and calibration, is undertaken by a suite of workstations and a parallel computer interconnected with a high-speed data net. The processor is based on the range-Doppler algorithm complemented with motion compensation and calibration algorithms. The processing time for a typical scene of $12 \times 12 \mathrm{~km}$ is approximately $2 \mathrm{~h}$ on a workstation and $20 \mathrm{~min}$ on the parallel computer. Various software packages for data quality analysis and visualization have been implemented, including point target analysis software also used for the external calibration.

Postprocessing: The standard postprocessor output product, includes scattering matrix data and covariance matrix data [21]. 
The scattering matrix $\mathbf{S}$ is a $2 \times 2$ matrix of complex values $\left(S_{i j}\right)$, where $j \in\{\mathrm{H}, \mathrm{V}\}$ is the transmit polarization and $i \in\{\mathrm{H}, \mathrm{V}\}$ is the receive polarization. The scattering matrix data have a sample spacing of $1.5 \times 1.5 \mathrm{~m}$, but they are focused to a nominal resolution of $2 \times 2 \mathrm{~m}$ to suppress sidelobes.

The covariance matrix is a $3 \times 3$ matrix as the HV- and VH-channels hold the same information for reciprocal targets

$$
\begin{aligned}
\mathbf{C} & =\left\langle\left[\begin{array}{l}
S_{h h} \\
S_{h v} \\
S_{v v}
\end{array}\right] \cdot\left[\begin{array}{lll}
S_{h h}^{*} & S_{h v}^{*} & S_{v v}^{*}
\end{array}\right]\right\rangle \\
& =\left[\begin{array}{lll}
\left\langle S_{h h} S_{h h}^{*}\right\rangle & \left\langle S_{h h} S_{h v}^{*}\right\rangle & \left\langle S_{h h} S_{v v}^{*}\right\rangle \\
\left\langle S_{h v} S_{h h}^{*}\right\rangle & \left\langle S_{h v} S_{h v}^{*}\right\rangle & \left\langle S_{h v} S_{v v}^{*}\right\rangle \\
\left\langle S_{v v} S_{h h}^{*}\right\rangle & \left\langle S_{v v} S_{h v}^{*}\right\rangle & \left\langle S_{v v} S_{v v}^{*}\right\rangle
\end{array}\right]
\end{aligned}
$$

where $\langle x\rangle$ is the expectation value of the stochastic quantity $x$ and $x^{*}$ is the complex conjugate of $x$. The covariance matrix is seen to be an hermitian matrix, and consequently, it is uniquely defined by the three real elements in the diagonal and the three complex elements above the diagonal. When calculating the covariance matrix in practice, the average of the two polarimetrically calibrated cross-polarized scattering matrix images (i.e., the complex sum divided by two for every pixel) is used to improve the signal-to-noise ratio. The six different product images are spatially averaged and resampled at a $5 \times$ 5 -m ground pixel spacing using a low-pass filter. This filter has a fixed length in the slant range domain to obtain a range independent speckle reduction, i.e., the equivalent number of looks is constant. It should be noted that the covariance data are ground range projected without taking the terrain slope into account.

Hardcopy imagery is generated either with a 300-dpi dye sublimation color printer or with a film recorder. The latter can handle color images with up to $8800 \times 9600$ pixels. The images in this paper (Figs. 7-10) are generated as gammatransformed ground range data (i.e., $\sigma_{0}$ divided by cosine of incidence angle), spatially averaged and subsampled to provide 1:50 000 imagery. The red, green, and blue colors represent the cross-pol, the HH-, and VV-intensities. The red intensity is the coherent sum of the HV- and the VH-channel intensities, i.e., the cross-pol channel is effectively amplified by $6 \mathrm{~dB}$. The three resulting channels have been raised to a power of 0.4 and linearly transformed by mapping gamma $=-3.5 \mathrm{~dB}$ $\left(\mathrm{m}^{2} / \mathrm{m}^{2}\right)$ onto 255 . All larger values are saturated. Finally, the color saturation is increased by $40 \%$.

\section{B. Calibration}

An absolute, polarimetric calibration is applied to EMISAR data. After the absolute radiometric calibration, the radar cross section in square meters divided by $4 \pi$ is found as the energy of a point target, i.e., the sum of the pixel intensities within the mainlobe multiplied by the pixel size of $2.25 \mathrm{~m}^{2}$. Using the energy rather than the peak intensity implies that, for a homogeneous distributed target, the ensemble average of the pixel intensity (i.e., $I^{2}+Q^{2}$ for every pixel) equals the radar brightness divided by $4 \pi$. The radar brightness in turn equals sigma-naught divided by sine of the local incidence angle [22]. The above definition of radiometric calibration is related to the well-known integral method, [23].

The covariance matrix data are calibrated such that the radar cross section of a point target is the sum of the pixel values in the mainlobe times the pixel size of $25 \mathrm{~m}^{2}$, and the sigmanaught value of a distributed target is the ensemble average of the pixels. Terrain slope is not taken into account by the sigma-naught calibration.

The internal calibration procedure developed for EMISAR comprises channel amplitude- and phase-imbalance correction, absolute radiometric calibration, STC calibration, and noise estimation, and it has a potential for range delay calibration as well.

For the calibration verification and for long-term stability, the internal calibration is complemented by corrections derived from regular external calibration experiments. These corrections are small and very similar from mission to mission (see Section VI-C and Table IV for more details) and have shown variation ( \pm standard deviation) of, e.g., the corrections on absolute calibration of less than $\pm 0.1 \mathrm{~dB}$ at $C$-band and $\pm 0.5 \mathrm{~dB}$ at $L$-band.

Internal Calibration: System calibration is often implemented by injecting a fixed-frequency calibration signal during mapping. This approach has two disadvantages. First, the system is only calibrated at a single frequency located outside the pulse spectrum, and secondly, major parts of the system cannot be included by this procedure.

Using calibration pulses with the same encoding as used for mapping, the system can be amplitude- and phase-calibrated over the full spectrum. The actual transfer functions of most components and, thereby, the entire SAR point target response, are taken into account. The built-in calibration paths allow the pulse-based procedure to calibrate almost the complete system, including both the TX and the RX, but not the antenna. The internal calibration cannot take place simultaneously with the mapping, and consequently, the system must be so stable that premap and postmap calibration pulses are adequate.

A one-dimensional version of the integral method is used to extract amplitude information from the compressed calibration pulses. The phase extracted is either the phase at the peak position or alternatively the phase of the complex pulse integral. In order to take the SAR point target response into account, it is crucial that the same calibration definition is applied to the internal calibration pulses as to the calibrated imagery (integral method/peak method).

Measured Signals: The individual subsystems, are modeled by complex $2 \times 2$ matrices equivalent to the scattering matrix $\mathbf{S}$, i.e., the $(i, j)$-element is the $i$-channel impulse response caused by a $j$-channel stimulus $i, j \in\{\mathrm{H}, \mathrm{V}\}$. Using $2 \times 2$ matrices is an approximation which presumes that the system is time invariant and, in particular, that the impulse responses of the various subsystems are the same during $\mathrm{V}$ - and H-transmission. These presumptions are fulfilled for EMISAR with accuracy, provided the data are corrected for the deliberate change in STC attenuation between reception of copolar and cross-polar data. 
In the mapping mode, as outlined in Fig. 4, the measured signals are [17]

$$
\mathbf{M}=\mathbf{R} * \mathbf{A} * \mathbf{E}_{a} * \mathbf{S} * \mathbf{G} * \mathbf{P} * \mathbf{T} * \mathbf{E}_{r}
$$

where $*$ denotes matrix convolution (on a pixel by pixel basis) that is identical to matrix multiplication except that the scalar elements are convolved rather than multiplied. The convolutions are two-dimensional (2-D) because some of the matrices are by nature functions of both range and azimuth.

$\mathbf{E}_{r}$ describes the range-encoded pulse just after the TWT. It is a diagonal matrix with identical elements. $\mathbf{T}$ is the transmitter matrix accounting for the transmission properties from the TWT to the polarization switch. It is also a diagonal matrix with identical elements since the $\mathrm{H}$ - and V-pulses are transmitted by the same hardware. $\mathbf{P}$ accounts for the polarization switch during transmission, and due to cross talk, this is in principle a full matrix with nonidentical elements. The complex antenna gain is characterized by $\mathbf{G}$ and, equivalently, the effective area of the receiving antenna by $\mathbf{A}$. $\mathbf{S}$ is the scene scattering matrix. $\mathbf{E}_{a}$ accounts for the azimuth encoding, i.e., the Doppler history, the range attenuation, and the range migration. Finally, the receiver matrix $\mathbf{R}$ contains the transmission parameters from the receiver antenna port through the receivers. Equivalent matrix equations can be derived for the three calibration modes.

System Calibration: Subsystems with bandwidths much larger than the pulse bandwidth have impulse responses approximately proportional to the Dirac delta function and hence convolution by the corresponding matrices degenerate to multiplication by matrices without the delta function, i.e., $\tilde{\mathbf{G}}, \tilde{\mathbf{A}}$, and $\tilde{\mathbf{P}}$ [17]. Thus, a calibrated measurement of the scattering matrix $\mathbf{S}$ is achieved by premultiplying and postmultiplying $\mathbf{M}$ by a series of matrices

$$
\hat{\mathbf{S}}=\left(\tilde{\mathbf{A}}^{-1} \mathbf{H}_{2 D}^{-1}\right) \mathbf{M}\left(\tilde{\mathbf{P}}^{-1} \tilde{\mathbf{G}}^{-1}\right) .
$$

In a calibration context, $\mathbf{H}_{2 D}$ can be expressed in terms of the energy and phases of the pulse-compressed internal calibration signals, the directional couplers, and the calibration attenuator in Fig. 4. These passive components must be measured in the laboratory, while all other parameters like TX and RX gains, losses, and impulse responses are covered by the internal calibration.

Antenna Calibration: The antennas, which are out of reach for the internal calibration procedures, have been calibrated to an accuracy of $0.1 \mathrm{~dB}$ on the directivity and $0.2 \mathrm{~dB}$ on the absolute gain in the ESA-TUD Spherical Near-Field Antenna Test Facility, [24]. So far, the cross-polarization terms of the antenna gains have not been included in the calibration as the inherent antenna cross-polarization isolation is sufficient to exceed specifications.

\section{VERIFICATION}

The performance evaluation is based on calibration experiments observing trihedrals and dihedrals deployed at Foulum, Denmark. The 2-m trihedrals (short side of triangles) and the 0.9-m dihedrals (square plates) were deployed at three different slant ranges, and the dihedrals were oriented at 45 and $22.5^{\circ}$
TABLE II

$L$ - And $C$-BAnd Impulse Response Statistics Based on

\begin{tabular}{|c|c|c|c|}
\hline L-band & & azimuth & range \\
\hline $3 \mathrm{~dB}$ resolution & (m) & $2.05 \pm 0.02$ & $1.98 \pm 0.02$ \\
\hline PSLR & $(\mathrm{dB})$ & $-25.2 \pm 2.0$ & $-25.8 \pm 1.3$ \\
\hline ISLR & (dB) & $-25.1 \pm 2.4$ & $-22.8 \pm 1.7$ \\
\hline C-band & & azimuth & range \\
\hline $3 \mathrm{~dB}$ resolution & $(\mathrm{m})$ & $1.97 \pm 0.01$ & $2.09 \pm 0.01$ \\
\hline PSLR & (dB) & $-31.9 \pm 2.4$ & $-30.9 \pm 2.1$ \\
\hline ISLR & (dB) & $-30.8 \pm 0.8$ & $-29.0 \pm 1.2$ \\
\hline
\end{tabular}
2.0-m Trihedrals (Average \pm Standard Deviation)

orientation angles to allow the channel balance to be analyzed. The calibration corner reflectors were identified in the focused imagery and examined with point target analysis software. Finally, the cross talk was assessed using distributed targets.

\section{A. Point Target Response}

Table II summarizes the results obtained for the 3-dB resolution, the peak side lobe ratio (PSLR), and the integrated side lobe ratio (ISLR) using the copolar trihedral responses. These quantities are computed from range and azimuth profiles through the peak of the interpolated data $[64 \times 64$ pixels around the peak interpolated to $1024 \times 1024$ pixels using Fast Fourier Transform (FFT)]. The main lobe width is defined as 3.15 times the $3-\mathrm{dB}$ width, i.e., slightly more than the theoretical zero-zero width (Hamming weighting is used). The $L$-band azimuth main lobe appears slightly wider, and the measured peak sidelobe is actually part of the main lobe. The side lobes are confined to \pm 10 times the 3 - $\mathrm{dB}$ width from the pulse peak. This confinement will, if applied to the theoretically expected impulse response function, lead to a $2 \mathrm{~dB}$ smaller ISLR value than if the integration had been continued to infinity, but limiting the analysis window is necessary due to the background clutter.

Ghost echoes caused by azimuth ambiguity were not visible, neither at the positions corresponding to the original PRF nor at the positions corresponding to the effective PRF after azimuth prefiltering. The former depend on the antenna azimuth pattern, and the latter on the azimuth prefilter. Since the root mean square (rms) clutter was 45 to $50 \mathrm{~dB}$ below the peak of the $2.0-\mathrm{m}$ trihedrals, it is concluded that the azimuth ambiguity ratio is better than the specified $-30 \mathrm{~dB}$.

\section{B. System Sensitivity}

The sensitivity of the $C$-band polarimetric system has been computed from the input noise level, which is measured just before and after a mapping. At $20-\mathrm{km}$ range, which is a typical mapping geometry, the noise equivalent beta-naught is about $-36 \mathrm{~dB}$ and, at $80-\mathrm{km}$ range, it is $-18 \mathrm{~dB}$. At $L$-band, the corresponding figures are -45 and $-27 \mathrm{~dB}$. Figs. 5 and 6 show the $L$ - and $C$-band performance at the normal mapping geometry, expressed by beta-naught $\left(\beta_{0}=\sigma_{0} / \sin [\right.$ incidence angle]) for the whole swath, assuming flat horizontal earth. The mapping geometry implies a difference between the near-range and the far-range look angles that exceeds the width of the antenna elevation pattern, and consequently, the noise equivalent sigma-naught degrades somewhat at the swath edges. 


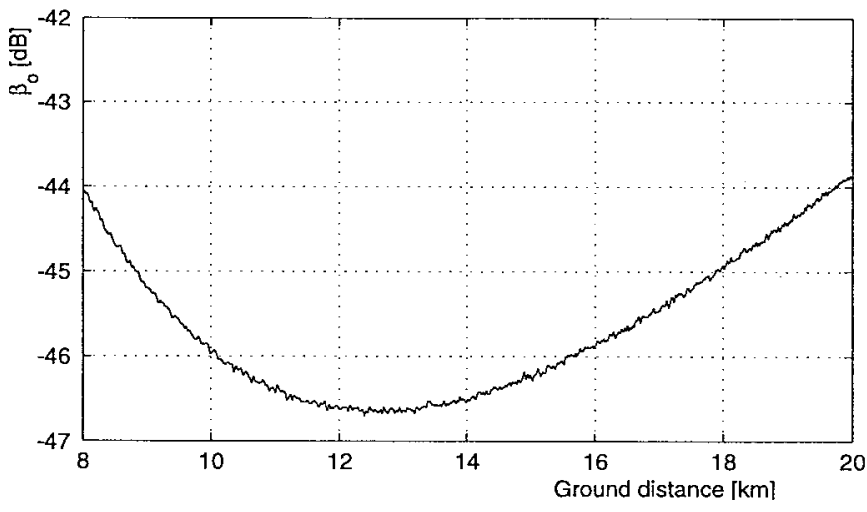

Fig. 5. Noise equivalent $\beta_{0}$ versus slant range at normal mapping geometry. $L$-band, altitude $12400 \mathrm{~m}$, antenna depression $36.0^{\circ}$.

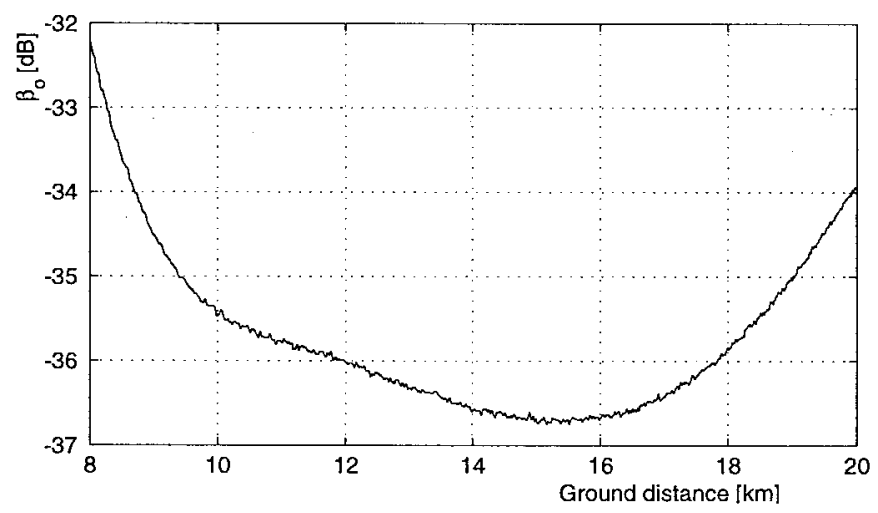

Fig. 6. Noise equivalent $\beta_{0}$ versus slant range at normal mapping geometry. $C$-band, altitude $12400 \mathrm{~m}$, antenna depression $41.16^{\circ}$.

TABLE III

Drift of Internal Calibration Signals from Premap to Postmap

\begin{tabular}{l|l|l|l}
\hline Frequency & Normal calibration & Extended inner loop & Extended outer loop \\
\hline L-band [amplitude, & $-0.12 \pm 0.02 \mathrm{~dB}$ & $-0.01 \pm 0.01 \mathrm{~dB}$ & $-0.08 \pm 0.03 \mathrm{~dB}$ \\
phase] & $-0.01 \pm 0.08^{\circ}$ & $+0.01 \pm 0.02^{\circ}$ & $-0.27 \pm 0.15^{\circ}$ \\
\hline C-band [amplitude, & $+0.02 \pm 0.02 \mathrm{~dB}$ & $+0.00 \pm 0.03 \mathrm{~dB}$ & $-0.06 \pm 0.09 \mathrm{~dB}$ \\
phase] & $-0.17 \pm 0.12^{\circ}$ & $-0.06 \pm 0.25^{\circ}$ & $-3.54 \pm 0.60^{\circ}$ \\
\hline
\end{tabular}

\section{Channel Imbalance and Absolute Calibration}

Since the EMISAR calibration basically relies on internal calibration signals acquired just before and just after every mapping, system stability during mapping is crucial. This stability has been evaluated in terms of the amplitude and phase drifts from premap calibration to postmap calibration. Table III presents statistics on seven data sets from a $C$-band mission and ten data sets from an $L$-band mission.

In order to assess the polarimetric calibration, the measured, calibrated scattering matrix is modeled as

$$
\begin{aligned}
\hat{\mathbf{S}} & =k \mathbf{B}_{r x} \mathbf{X}_{r x} \mathbf{S X}_{t x} \mathbf{B}_{t x} \\
& =k\left[\begin{array}{cc}
1 & 0 \\
0 & f_{r x}
\end{array}\right]\left[\begin{array}{cc}
1 & w \\
u & 1
\end{array}\right]\left[\begin{array}{ll}
S_{h h} & S_{h v} \\
S_{v h} & S_{v v}
\end{array}\right]\left[\begin{array}{ll}
1 & z \\
v & 1
\end{array}\right]\left[\begin{array}{cc}
1 & 0 \\
0 & f_{t x}
\end{array}\right] .
\end{aligned}
$$

Here $k$ accounts for the residual absolute calibration error and $\mathbf{B}_{t x}$ and $\mathbf{B}_{r x}$ account for the residual channel imbalance on the transmit and receive sides, respectively. $\mathbf{X}_{t x}$ and $\mathbf{X}_{r x}$ account for the cross talk on the transmit and receive sides,
TABLE IV

Standard Deviation of Calibration Errors After Internal Calibration

\begin{tabular}{l|l|l|l}
\hline Frequency & TX imbalance $\left(\mathrm{f}_{\mathrm{s}}\right)$ & RX imbalance $\left(\mathrm{f}_{\mathrm{\alpha}}\right)$ & Absolute cal. $(\mathbf{k})$ \\
\hline L-band & $0.13 \mathrm{~dB} 1.05^{\circ}$ & $0.21 \mathrm{~dB} 2.13^{\circ}$ & $0.49 \mathrm{~dB}$ \\
\hline C-band & $0.09 \mathrm{~dB} 0.85^{\circ}$ & $0.30 \mathrm{~dB} 4.25^{\circ}$ & $0.10 \mathrm{~dB}$ \\
\hline
\end{tabular}

respectively, and $\mathbf{S}$ is the scattering matrix to be measured. All parameters are complex numbers.

It can be shown [25] that the channel imbalance parameters can be computed from the scattering matrix elements measured for a trihedral and a dihedral with $45^{\circ}$ orientation angle. An additional dihedral with an orientation different from a multiple of $45^{\circ}$, e.g., $22.5^{\circ}$, is needed to eliminate a $180^{\circ}$ ambiguity in the phase difference between copolarized and cross-polarized channels. The absolute radiometric calibration error $|k|$ has been estimated for each of the trihedrals by comparing the measured data with the RCS expected when correcting for the mismatch of the SAR and reflector look angles. Instead of using a $45^{\circ}$ orientated dihedral, a distributed target with a significant cross polarization can be used. This is often attractive because the accuracy of the dihedral pointing is critical.

The map-to-map calibration stability has been examined using the average of the calibration factors found at the three ranges. The $L$-band statistics are based on nine scenes from five missions, and the $C$-band statistics are based on eight scenes from four missions in 1995, i.e., the antennas have been mounted and dismounted several times. When using only internal calibration, the standard deviations of the absolute calibration and the channel imbalance are as listed in Table IV. Obviously, a single external calibration per mission suffices. The results indicate that external calibration is hardly a necessity on each mission; however, it is still desired as a means to confirm the expected calibration performance.

\section{Cross-Talk Calibration}

Cross-talk calibration may be carried out using distributed targets for which the true copolarized and cross-polarized returns are uncorrelated. This requirement is met by natural targets with azimuthal symmetry [26]. A number of algorithms have been proposed in the literature, e.g., [27]-[29]. Unlike the other algorithms, the algorithm presented in [28] is noniterative, and since it has previously shown good results for AIRSAR data [30], it has been used to estimate the rather small residual cross talk from the EMISAR data [31] based on data acquired at calibration sites at DLR, Oberpfaffenhofen, Germany (Fig. 7), and Foulum (Fig. 8).

The algorithm estimates the four cross-talk terms after the channel imbalance correction, i.e., $u, v, w$, and $z$, using 100 lines of 8192 samples for each estimate of the crosstalk terms. All terms are below approximately $-30 \mathrm{~dB}$, and they are basically independent of range. A correction has been performed with a modified algorithm that produces two cross-polarized channels instead of one channel for the original algorithm. The amplitude of the terms estimated after the cross-talk correction are below $-38 \mathrm{~dB}$ worst case and typically around $-41 \mathrm{~dB}[31]$. 


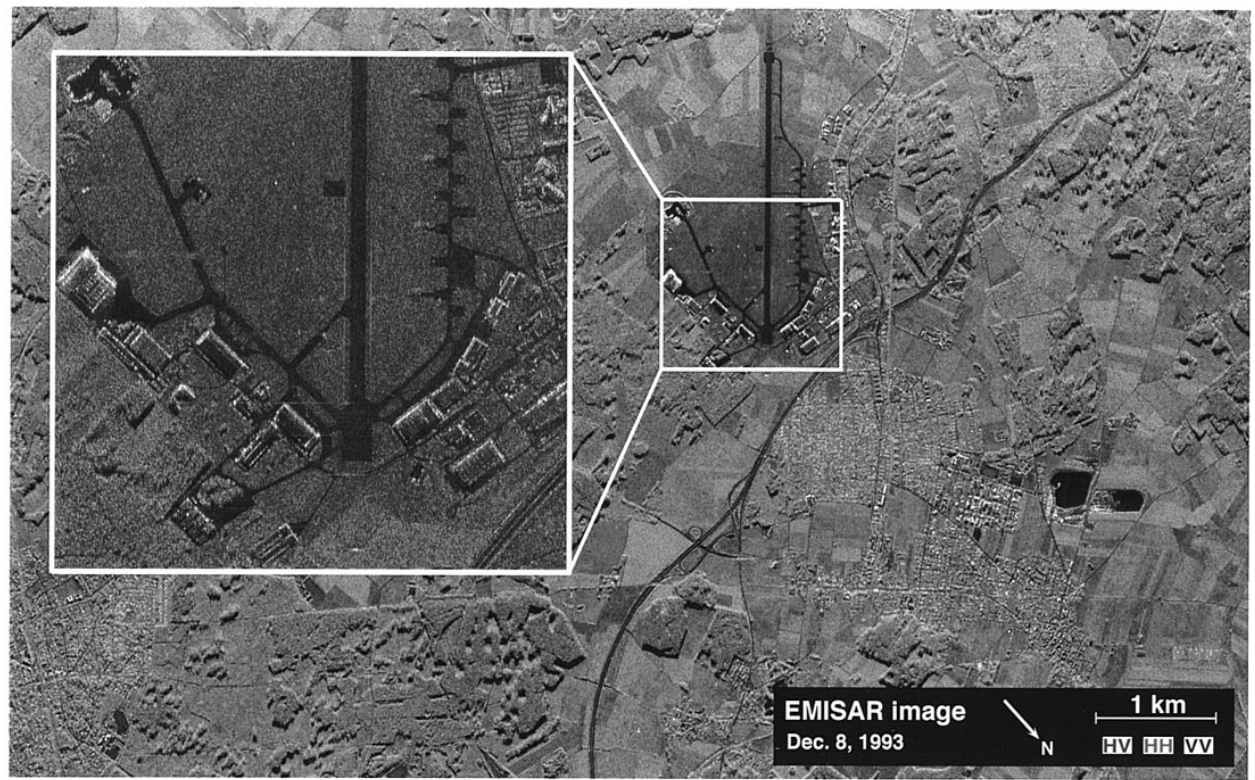

Fig. 7. Polarimetric $C$-band SAR image acquired as part of an ESA calibration experiment December 8, 1993, of the DLR test site. VV-polarization is blue, HH is green, and $\mathrm{HV}+\mathrm{VH}$ is red. The insert displays an airfield with trihedrals (cyan), dihedrals at $45^{\circ}$ orientation (red), and dihedrals at $22.5^{\circ}$ orientation (white).

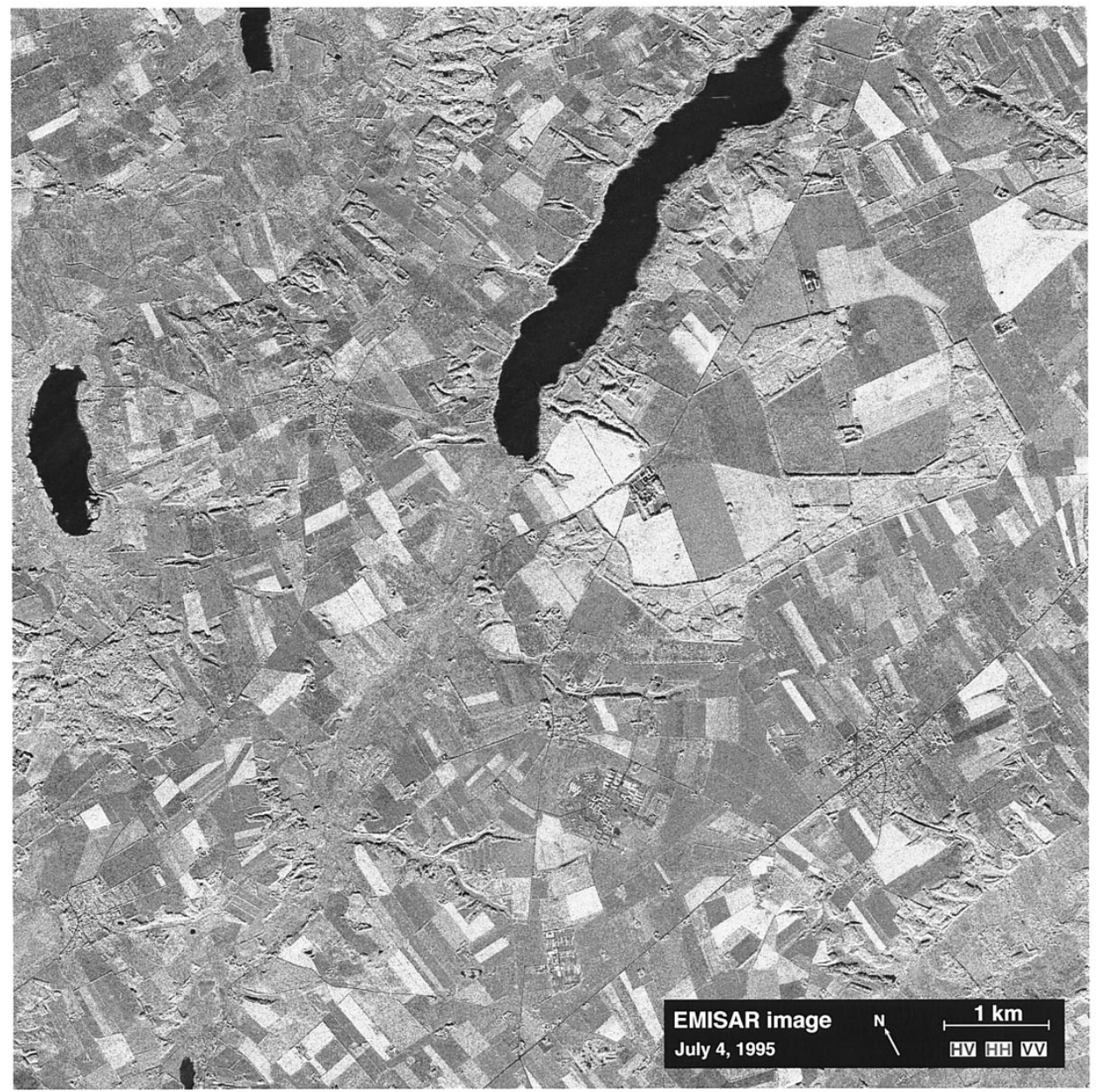

Fig. 8. Polarimetric $C$-band SAR image of the RCF agricultural test and calibration site acquired on July 4, 1995, when the grain crops are almost ripe. The standard DCRS image presentation format is used in which the VV-polarization is blue, HH is green, and HV $+\mathrm{VH}$ is red. 


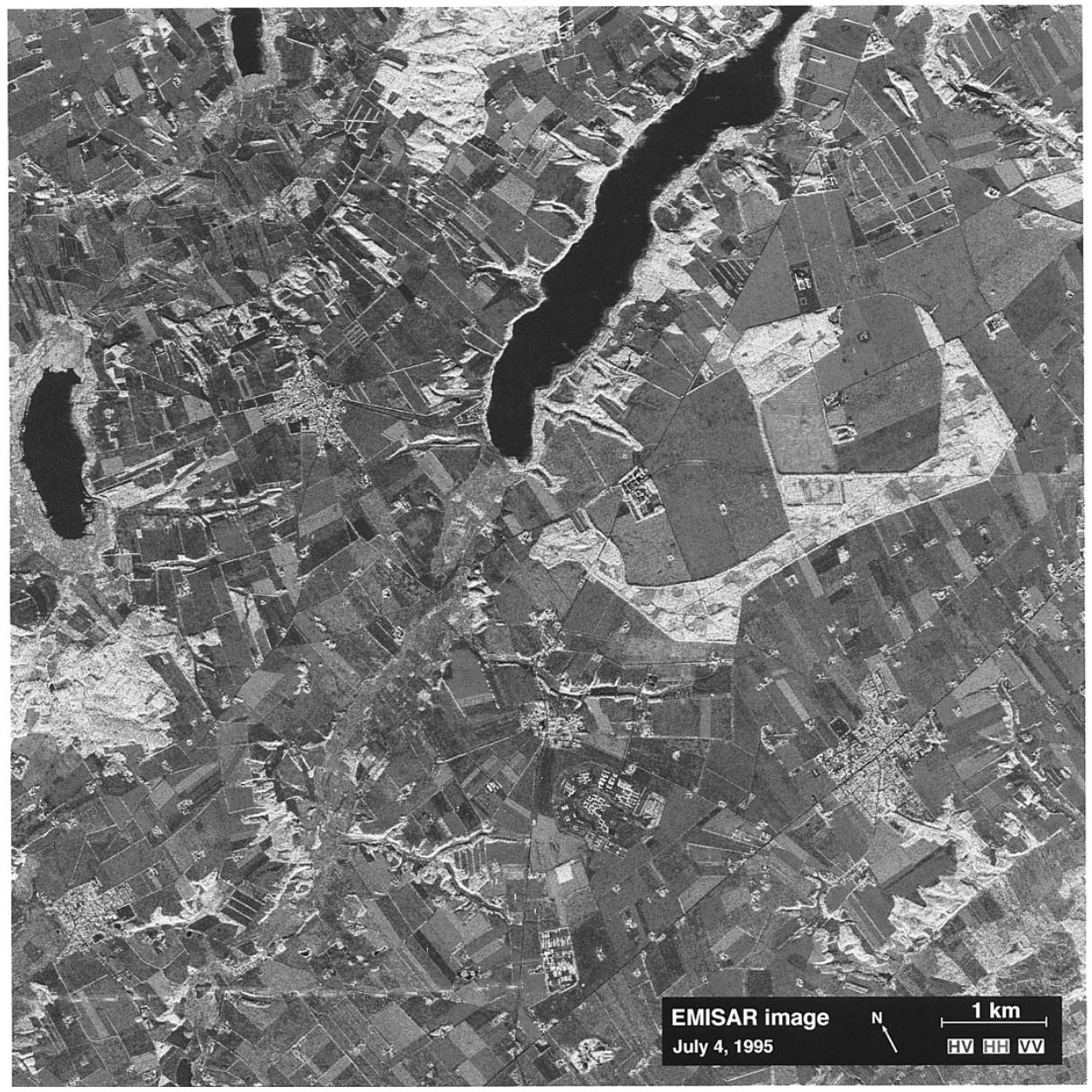

Fig. 9. Polarimetric $L$-band SAR image of the RCF agricultural test site acquired on July 4, 1995. Same image presentation as in Fig. 8.

Recent results [4] seem to question that natural targets in general can be assumed to have sufficient azimuthal symmetry. Therefore, EMISAR data are usually not cross-talk corrected as the intrinsic low cross talk of the system already exceeds specifications.

\section{APPLICATIONS}

\section{A. DCRS Research}

EMISAR is used for the dual purpose of serving as a testbed for SAR research and as a tool for acquiring data for the scientific studies of DCRS. A common denominator for the studies is that the experiment sites are being revisited several times to make it possible to study the benefit of multitemporal data sets, i.e., to study seasonal changes and environmental variations. The active research areas where DCRS applies the airborne SAR system are microwave sea ice signatures [32], glacier dynamic [33], geologic mapping in Greenland [34], the dynamics of sand dunes, estimation of surface roughness, plant and soil mapping [35], [36], and remote sensing and landscape ecology.

Figs. 8 and 9 show examples (from the plant and soil mapping) of the benefit achieved from fully polarimetric data with dual frequency. The two images were acquired from the same scene on the same day with $C$ - and $L$-band, respectively. It is obvious even from a visual inspection of these images that they offer complementary information. The $L$-band image is more blue in the agricultural areas, meaning that the VV-polarization gives stronger reflections than at $C$-band, but a comparison of the individual fields reveals that this is not systematic. The addition of a second frequency adds essential new information. Fig. 10 shows the same scene but acquired (using $C$-band) a little more than two months earlier. Again, the image gives completely different information, documenting that crop identification may be considerably augmented by the availability of time series. The three images were acquired using identical mapping geometry. Some quick-look EMISAR images are displayed on the Internet (http://www.dcrs.dtu.dk/) with information on how full-resolution digital data can be obtained for noncommercial use.

\section{B. European Multisensor Airborne Campaign}

In addition to DCRS's own scientific studies, the system has been used in experiments supported by ESA. This in particular includes the European Multisensor Airborne Campaign (EMAC) [4], [5]. During this campaign, EMISAR has acquired data for studies in agricultural areas, snow and glacier areas, and over sea ice. EMAC quick-look images are displayed on the Internet (http://www.estec.esa.nl/vrwww/emac/EMAC.html) together with information on availability. 


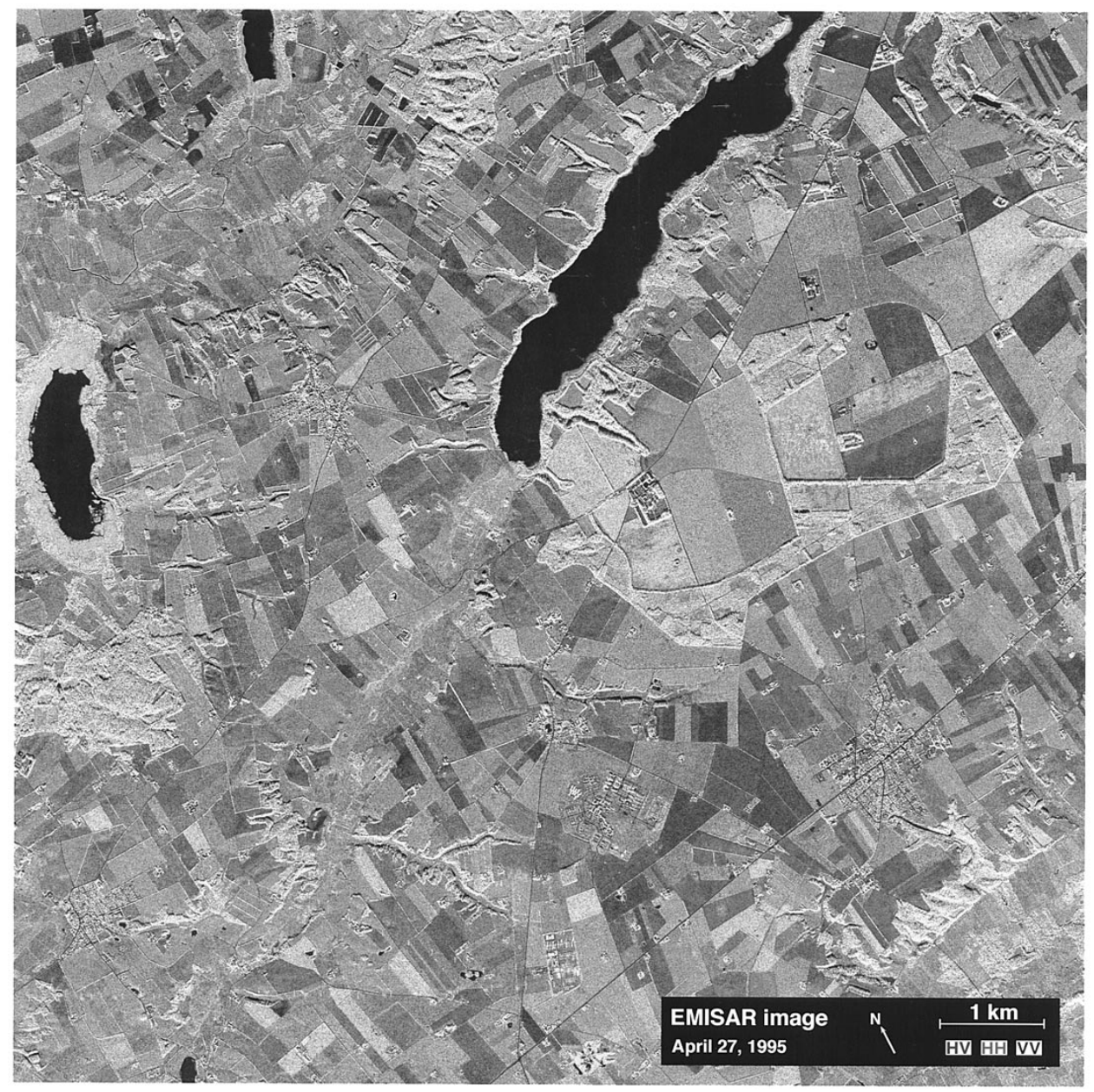

Fig. 10. Polarimetric $C$-band SAR image of the RCF agricultural test site acquired on April 27, 1995, very early in the growth season. Same image presentation as in Fig. 8.

\section{FutURE OUTLOOK}

The dual-frequency polarimetric SAR system discussed is now used for ongoing measurements programs, but simultaneously several system enhancements are being implemented or being investigated. Work on airborne repeattrack interferometry has been in progress for some time [7]. Airborne repeat-track interferometry involves significant difficulties technically as it requires an ability to fly and repeat a preselected track with meter level accuracy, and the motion measurements and compensation algorithms must be extremely accurate to enable precise coregistration of the two images and provide millimeter-level accuracy for the baseline. The technique does, however, offer the potential to generate height maps with extremely low height noise, and multiple passes provide a capability to measure simultaneous topography and displacements, a capability presently being used for DCRS's glacier studies. A single-pass cross-track interferometry capability has also been implemented, and testing and software development is in progress. As the interferogram in this case is formed from signals received by two antennas rigidly connected (by the fuselage of the aircraft), this technique offers much fewer technical obstacles. However, the baselines that can be implemented are limited due to the constraints of installing multiple antennas on a relatively small fuselage. The present DCRS system features a $1.1-\mathrm{m}$ long baseline. After correction of systematic errors (caused by multipath on the aircraft and channel cross coupling), a 1-3-m height resolution on a 10-m horizontal grid is achieved when operating from $41000 \mathrm{ft}$, but significantly better resolution, generally better than $1 \mathrm{~m}$, has been observed when operating from a $25000-\mathrm{ft}$ altitude.

Until early 1996, the system had only been operated with one frequency active at the time. Therefore, acquiring two frequencies over a given site has required two passes. Presently, upgrades are being implemented that allow simultaneous fullswath operation at both frequencies by acquiring $L$-band polarimetric data on an antenna installed in the pod, while either $C$-band polarimetric data or $C$-band single-polarization interferometric data are collected on the flush-mounted antennas. The work on absolute calibration of data from the flush-mounted antennas is in progress.

\section{ACKNOWLEDGMENT}

The authors would like to acknowledge other members of the SAR team: S. Kristensen and J. Grinder-Pedersen (offline SAR processor), H. Skriver (cross-talk elimination), A. Netterstrøm, N. Andersen, and N. Vardi (digital hardware and embedded software), M. Dich, J. Rohde, and B. Laursen 
(antenna and analog electronics), and K. Christensen and B. Brændstrup (technical implementation), as well as the contributions and know-how from colleagues at the Department of Electromagnetic Systems, especially the staff of the antenna group and the workshop.

The project has benefited extensively by the aircraft and other support from the Danish Defense and in particular the Royal Danish Air Force. The European Space Agency, represented by ESTEC, has sponsored various verification and application flights aiming at acquiring high-quality remotesensing data for a number of European scientists.

Finally, the establishment of the Danish Center for Remote Sensing, sponsored by the Danish National Research Foundation, has provided the opportunity to thoroughly verify the stability of the SAR system and use the SAR for a multitude of remote-sensing applications.

\section{REFERENCES}

[1] J. J. Kovaly, Synthetic Aperture Radar. Norwood, MA: Artech House, 1976.

[2] H. J. Kramer, Observation of the Earth and Its Environment, Survey of Missions and Sensors, 2nd ed. Berlin, Germany: Springer-Verlag, 1994.

[3] S. N. Madsen, E. L. Christensen, N. Skou, and J. Dall, "The Danish SAR system; Design and initial tests," IEEE Trans. Geosci. Remote Sensing, vol. 29, pp. 417-426, May 1991.

[4] J. Dall, S. N. Madsen, H. Skriver, S. S. Kristensen, and E. L. Christensen, EMISAR Deployment in the EMAC'94 Campaign, Electromagn. Inst., Tech. Univ. Denmark, Lyngby, R 600, ESTEC Contract 11095/94/NL/CL, Sept. 1994.

[5] J. Dall, EMISAR Deployment in the EMAC'95 Campaign, Electromagnetics Inst., Tech. Univ. Denmark, Lyngby, R 631, ESTEC Contract 11579/95/NL/CN, May 1996.

[6] E. L. Christensen and M. Dich, "SAR antenna design for ambiguityand multipath suppression," in Proc. IGARSS'93, Int. Geosci. Remote Sensing Symp., Tokyo, Japan, vol. 2, pp. 784-787.

[7] S. N. Madsen, N. Skou, J. Granholm, K. W. Woelders, and E. L. Christensen, "A system for airborne SAR interferometry," in Proc. AE $\ddot{U}$, 1996, vol. 50, no. 2, pp. 106-111 and in Proc. Eusar'96, Königswinter, Germany, pp. 171-176

[8] A. Freeman, "SAR calibration: An overview," IEEE Trans. Geosci. Remote Sensing, vol. 30, pp. 1107-1121, Nov. 1992.

[9] P. C. Dubois, D. Evans, and J. van Zyl, "Approach to derivation of SIRC science requirements for calibration," IEEE Trans. Geosci. Remote Sensing, vol. 30, pp. 1145-1149, Nov. 1992.

[10] M. C. Dobson, F. T. Ulaby, T. Le Toan, E. S. Kasischke, and N. Christensen, "Dependence of radar backscatter on coniferous forest biomass," IEEE Trans. Geosci. Remote Sensing, vol. 30, pp. 412-415, Mar. 1992.

[11] A. Netterstrøm and E. L. Christensen, "Correction for quadrature errors," in Proc. IGARSS'94, Int. Geosci. Remote Sensing Symp., Pasadena, CA, pp. 909-911.

[12] K. W. Woelders and J. Granholm, "Design and performance of a duallinearly polarized C-band microstrip array antenna," in Proc. 2nd Int. Workshop Radar Polarimetry, Nantes, France, Sept. 1992, pp. 369-378.

[13] J. Granholm, K. W. Woelders, M. Dich, and E. L. Christensen, "Microstrip antenna for polarimetric C-band SAR," in IEEE AP-S Int. Symp. URSI Radio Sci. Mtg., Seattle, WA, June 19-24, 1994.

[14] N. Skou, J. Granholm, K. Woelders, J. Rohde, J. Dall, and E. L. Christensen, "A high resolution polarimetric $L$-band SAR-Design and first results," in Proc. IGARSS'95, Int. Geosci. Remote Sensing Symp., Firenze, Italy, vol. 3, pp. 1779-1782.

[15] K. W. Woelders and J. Granholm, "Cross-polarization and sidelobe suppression in dual linear polarized antenna arrays," IEEE Trans. Antennas Propagat., vol. 45, pp. 1721-1740, Dec. 1997.

[16] N. Skou, "The Danish polarimetric SAR system," in Proc. 2nd Int. Workshop Radar Polarimetry, Nantes, France, Sept. 8-10, 1992, pp. 525-533.

[17] J. Dall, N. Skou, and E. L. Christensen, "Pulse-based internal calibration of polarimetric SAR," in Proc. IGARSS'94, Int. Geosci. Remote Sensing Symp., Pasadena, CA, pp. 2205-2208.
[18] S. N. Madsen, "Estimating the Doppler centroid of SAR data," IEEE Trans. Aerosp. Electron. Syst., vol. 25, pp. 134-140, July 1989.

[19] J. Dall, J. H. Jørgensen, E. L. Christensen, and S. N. Madsen, "Realtime processor for the Danish airborne SAR," Proc. Inst. Elect. Eng., pp. 115-121, Apr. 1992

[20] J. Dall, J. H. Jørgensen, A. Netterstrøm, N. Vardi, E. L. Christensen, and S. N. Madsen, "The Danish real-time SAR processor: First results," in Proc. IGARSS'93, Int. Geosci. Remote Sensing Symp., Tokyo, Japan, vol. 3, pp. 1401-1403.

[21] J. Dall, EMISAR Data Description, Electromagn. Inst., Tech. Univ. Denmark, Lyngby, R 633, May 1996.

[22] R. K. Raney, T. Freeman, R. W. Hawkins, and R. Bamler, "A plea for radar brightness," in Proc. IGARSS'94 Int. Geosci. Remote Sensing Symp., Pasadena, CA, vol. 2, pp. 1090-1092.

[23] A. L. Gray, P. W. Vachon, C. E. Livingstone, and T. I. Lukowski, "Synthetic aperture radar calibration using reference reflectors," IEEE Trans. Geosci. Remote Sensing, vol. 28, pp. 374-383, May 1990.

[24] J. E. Hansen, Ed., Spherical Near Field Antenna Measurements. London, U.K.: Peter Peregrinus, 1988.

[25] J. Dall, Polarimetric Calibration with Corner Reflectors, Electromagn. Inst., Tech. Univ. Denmark, Lyngby, R575, Feb. 1994.

[26] M. Borgeaud, R. T. Shin, and J. A. Kong, "Theoretical models for polarimetric radar clutter," J. Electromagn. Waves Applicat., vol. 1, pp. 73-89, 1987

[27] J. Klein, "Calibration of complex polarimetric SAR imagery using backscatter correlations," IEEE Trans. Aerosp. Electron. Syst., vol. 28, pp. 183-194, Jan. 1992.

[28] S. Quegan, "A unified algorithm for phase and cross-talk calibration of polarimetric data-Theory and observations," IEEE Trans. Geosci. Remote Sensing, vol. 2, pp. 89-99, Jan. 1993.

[29] J. J. van Zyl, "Calibration of polarimetric radar images using only image parameters and trihedral corner reflector responses," IEEE Trans. Geosci. Remote Sensing, vol. 28, pp. 337-348, Mar. 1990.

[30] H. Skriver, H. B. Mortensen, and P. Gudmandsen, "Calibration and modeling of Maestro-1 polarimetric SAR data of a forest area in Les Landes, France," Int. J. Remote Sensing, vol. 15, no. 14, pp. 2737-2754, 1994.

[31] H. Skriver, J. Dall, S. N. Madsen, "External polarimetric calibration of the Danish polarimetric C-band SAR," in Proc. IGARSS'94, Int. Geosci. Remote Sensing Symp., Pasadena, CA, pp. 1105-1107.

[32] H. Skriver and L. T. Pedersen, "Polarimetric signatures of sea ice in the Greenland sea," in Proc. IGARSS'95 Int. Geosci. Remote Sensing Symp., Firenze, Italy, pp. 1792-1794.

[33] J. Mohr and S. N. Madsen, "Parametric estimation of time varying baselines in airborne interferometric SAR," in Proc. IGARSS'96 Int Geosci. Remote Sensing Symp., Lincoln, NE, pp. 677-679.

[34] J. Dall, S. N. Madsen, C. K. Brooks, and T. Nielsen, "Geologic mapping in Greenland with polarimetric SAR," in IGARSS'95 Int. Geosci. Remote Sensing Symp., Firenze, Italy, pp. 2206-2208.

[35] J. Ji, A. Thomsen, and H. Skriver, "Estimating soil moisture using the Danish polarimetric SAR," in Proc. IGARSS'95 Int. Geosci. Remote Sensing Symp., Firenze, Italy, pp. 942-944.

[36] H. Skriver, J. Dall, K. W. Woelders, A. Netterstrøm, and A. Thomsen, "A multi-temporal and multi-frequency study of polarimetric signatures of soil and crops," in Proc. Eusar'96, Königswinter, Germany, pp. $481-484$.

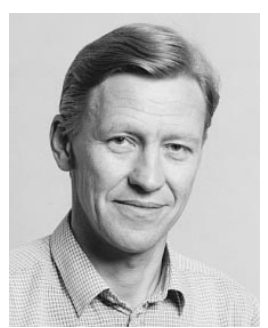

Erik Lintz Christensen (M'97) received the M.Sc.E.E. degree in 1966

He has been with the Electromagnetics Institute, now Department of Electromagnetic Systems (EMI), Technical University of Denmark, Lyngby, since 1968, where he is now an Associate Professor His work has covered many aspects of radar, radio communications, and high-frequency and microwave electronics. This includes the design of $60-$ and $300-\mathrm{MHz}$ radars for recording of the thickness of the inland ice of Greenland and Antarctica, equipment for measuring amplitude and phase of the transfer function of a $50-\mathrm{km}$ line-of-sight radio path at $15 \mathrm{GHz}$, and a system for measuring amplitude and phase of antenna near-field patterns. He is now Project Manager of the Danish Airborne SAR program. Since February 1994, he has been Co-Manager of the Danish Center for Remote Sensing, EMI, in collaboration with S. N. Madsen. 
Niels Skou (S'78-M'79-SM'96), for a photograph and biography, see p. 832 of the May 1998 issue of this Transactions.

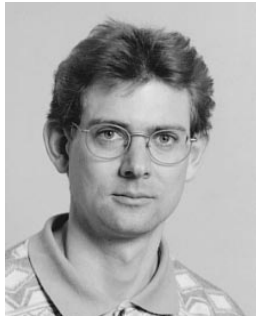

Jørgen Dall received the M.Sc.E.E. degree in 1984 and the Ph.D. degree in 1989.

$\mathrm{He}$ has been with the Electromagnetics Institute, now Department of Electromagnetic Systems (EMI), Technical University of Denmark, Lyngby, since 1984, where he conducted an ESA study of microwave instruments for planetary missions. Among his recent activities are the development of algorithms for polarimetric calibration of the Danish Airborne SAR (EMISAR) and technical management of a SAR processing facility for semioperational processing of EMISAR data. He was responsible for the development of a dedicated onboard full-resolution real-time processor for EMISAR, and prior to that, he implemented software processors for the SEASAT SAR and EMISAR systems. Other SAR activities have included development of a novel SAR autofocus algorithm and studies of fast transform and convolution algorithms for SAR processing. He is now leading the SAR processing group at the Danish Center for Remote Sensing, EMI.

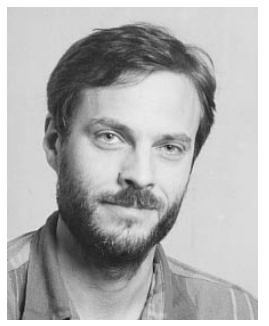

Kim Wildt Woelders received the M.S. degree in 1983 and the Ph.D. degree in 1988, both in electrical engineering, from the Technical University of Denmark, Lyngby.

$\mathrm{He}$ is currently a Senior Research Associate at the Electromagnetics Institute, now Department of Electromagnetic Systems (EMI), Technical University of Denmark. Since 1986, his work has primarily been concerned with various topics related to the development of the EMISAR system: slotted waveguide array antenna and dual-polarization microstrip antenna design, real-time system control computer implementation, system integration, and system operation.

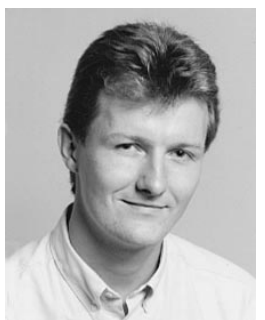

Jan Hjelm Jørgensen received the B.Sc.E.E. degree in 1984, the M.Sc.E.E. degree in 1988, and the Ph.D. degree in 1995.

He has been with the Electromagnetics Institute, now Department of Electromagnetic Systems (EMI), Technical University of Denmark, Lyngby, since 1988. Initially, he designed digital subsystems for the $C$-band SAR system, which had its maiden flight in late 1989. This SAR system was, in mid1992, augmented with a real-time processor, for which he was the main architect. He completed a two-year postdoctorate scholar position at the University of California, Santa Barbara, in 1997, where he researched implementation aspects of 40-gigabit/s asynchronous transfer mode (ATM) switch designs. He is currently a Senior Research Associate at the Danish Center for Remote Sensing, EMI, where he is working on SAR system design. His main research areas include distributed processing/control and digital signal processing and technology.

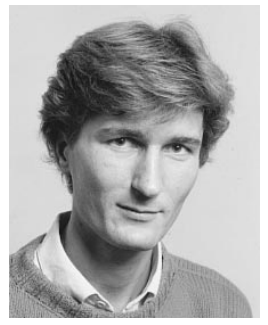

Johan Granholm (M'88) received the M.Sc.E.E degree from the Electromagnetics Institute, now Department of Electromagnetic Systems (EMI), Technical University of Denmark, Lyngby, in 1987.

He has been a Research Assistant at EMI since 1987. His main interest, and major contribution to the SAR systems, is the practical development of radio frequency and microwave components and subsystems, including the dual-polarized microstrip antennas with low cross polarization.

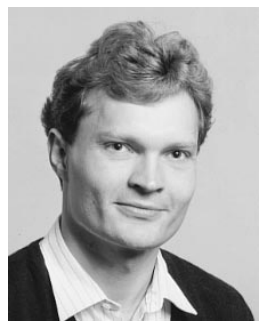

Søren Nørvang Madsen ( ' $^{\prime} 83-\mathrm{M}^{\prime} 84$ ) received the M.Sc.E.E. degree in 1982 and the Ph.D. degree in 1987.

He has been with the Electromagnetics Institute, now Department of Electromagnetic Systems (EMI), Technical University of Denmark, Lyngby, since 1982. His work has included all aspects of synthetic aperture radar (SAR), including development of preprocessors, analysis of basic properties of SAR images, postprocessing, and SAR systems design. From 1987 to 1989, he was an Associate Professor at EMI, working on the design of radar systems for mapping the earth and other planets as well as the application of digital signal processing systems in radar systems. He was the Initiator and Project Manager for the Danish Airborne SAR program from its start until he left EMI in 1990, when he joined NASA's Jet Propulsion Laboratory (JPL), Pasadena, CA. At JPL, he first worked on geolocating SEASAT and SIR-B SAR data, then lead the development of a SIR-C calibration processor prototype. He was also involved in the Magellan Venus radar mapper project. Since 1992, his main interest has been interferometric SAR systems. He has lead the developments of the processing systems for the JPL/NASA across-track interferometer (TOPSAR) as well as the ERIM IFSAR system. From 1993 to 1996, he split his time between JPL and EMI. At EMI, he is presently heading the Danish Center for Remote Sensing (DCRS) (in collaboration with E. L. Christensen), and his work involves all aspects relating to the airborne Danish dual-frequency polarimetric and interferometric SAR. At DCRS, he is also a Principal Investigator for two ERS-1/-2 satellite SAR studies. He is currently a Full Professor at EMI. 